\title{
Place conditioning with d-amphetamine: The effect of the CS-UCS interval and evidence of a place avoidance
}

\author{
ANNE-MARIE WALL, RILEY E. HINSON, EILEEN SCHMIDT, \\ CHRIS JOHNSTON, and ANGELA STREATHER \\ University of Western Ontario, London, Ontario, Canada
}

\begin{abstract}
In Experiment 1, a dose-response study of place conditioning with amphetamine was conducted. Male Sprague-Dawley rats receiving $0.0,0.05,0.1,0.5,2.0,5.0,7.5$, or $10.0 \mathrm{mg} / \mathrm{kg}$ of d-amphetamine underwent 104 -day cycles of place conditioning. On alternate days, each rat was injected with its designated dose of amphetamine while confined to its originally nonpreferred end of a three-compartment, straight alley box. On intervening days, each rat was injected with saline while confined to its originally preferred compartment. Following each 4-day cycle, a choice test was administered in which each rat was allowed $20 \mathrm{~min}$ of access to the entire alley box. Doses of amphetamine ( $\geq 0.5 \mathrm{mg} / \mathrm{kg}$ ) induced a significant avoidance of the compartment in which amphetamine had been administered. In Experiment 2, animals received 0.0, 0.5, 2.0, or $5.0 \mathrm{mg} / \mathrm{kg}$ of amphetamine and underwent place conditioning procedures identical to those for the animals in Experiment 1. Unlike in Experiment 1, the animals were given a single choice test following 10 4-day place conditioning cycles. All groups that received amphetamine exhibited a conditioned place avoidance. In Experiment 3, the effect of various CS-UCS intervals on place conditioning with $2.0 \mathrm{mg} / \mathrm{kg}$ of amphetamine was examined. Animals that received amphetamine immediately following their removal from the chamber exhibited a conditioned place avoidance.
\end{abstract}

Pharmacological place conditioning can be conceptualized as a Pavlovian conditioning procedure. In the typical place conditioning experiment, animals are confined to one end compartment of a straight alley box and injected with a drug. On alternate days, the animals are confined in the other distinctively different end compartment and injected with saline. Looked at as a classical conditioning procedure, the effects of the drug are the unconditional stimuli (UCSs), which are paired with the conditional stimuli (CSs) consisting of the stimuli of the end compartment in which the drug is injected. Following a number of drug injection trials alternating with saline injection trials, a test is given in which the animal is allowed free access to the entire straight alley box. The main dependent measure is the amount of time the animal spends in the two end compartments. If, following a history of end-compartment-drug-effect pairings, an animal spends more time in the drug-associated end compartment than in the saline-associated compartment, this is identified as a conditioned place preference and is taken as evidence that the drug has positive reinforcing effects.

A number of drugs have been investigated in the place conditioning paradigm, most notably amphetamine and morphine. With regard to amphetamine, several studies

Requests for reprints should be addressed to Anne-Marie Wall, Department of Psychology, University of Western Ontario, London, Ontario N6A 5C2, Canada.
(Carr \& White, 1983; Di Scala, Martin-Iverson, Phillips, \& Fibiger, 1985; Gilbert \& Cooper, 1983; Leone \& Di Chiara, 1987; Mackey \& Van der Kooy, 1985; Mithani, Martin-Iverson, Phillips, \& Fibiger, 1986; Sherman, Roberts, Roskam, \& Holman, 1980; Spyraki, Fibiger, \& Phillips, 1982) have provided evidence for a conditioned place preference, and this has been taken as evidence that amphetamine has some positive reinforcing effect. Although less frequently reported, there is also evidence of amphetamine's either failing to produce a conditioned place preference (Martin \& Ellinwood, 1974; Schenk, Hunt, Malovechko, Robertson, Klukowski, \& Amit, 1986), or, in fact, producing a conditioned place avoidance (Martin \& Ellinwood, 1974). In the case of a conditioned place avoidance, the animal spends less time in the drug-associated side than in the saline-associated side. The fact that both conditioned place preferences and avoidances may occur with amphetamine should not be surprising, since there is evidence from other paradigms that amphetamine has both positive and negative effects. For example, amphetamine has been shown to be an effective reinforcer in self-administration studies (Balster \& Schuster, 1973; Pickens, 1968; Wise, Yokel, \& De Witt, 1976), but amphetamine also produces a conditioned taste aversion (Berger, 1972; Cappell \& LeBlanc, 1971, 1973; Carey, 1973; Carey \& Goodall, 1973; Le Magnen, 1969).

There is some research on the effect of dose on place conditioning with amphetamine (e.g., see Gilbert \& 
Cooper, 1983; Spyraki et al., 1982). Importantly, these studies have shown that conditioned place preferences only occur within a certain range of doses. Just as importantly, other studies have furnished evidence of either no conditioned preference or conditioned avoidance within the same range (e.g., see Martin \& Ellinwood, 1974). It is well known that the acute effects of amphetamine vary from only minor behavioral activation with low doses to restricted, stereotyped movements and convulsions with high doses (e.g., see Ellinwood \& Balster, 1974; Fog, 1970). It is also well known that the effects of amphetamine change over the course of repeated administrations. Some effects (e.g., anorexia) show tolerance, while others exhibit sensitization. For example, a dose of amphetamine that acutely may produce only mild behavioral activation may, after repeated administrations, produce the stereotyped behaviors and convulsions produced acutely by much higher doses (Segal \& Mandell, 1974; Segal, Weinberger, Cahill, \& McCunney, 1980). In most studies of place conditioning with amphetamine, only a small number of injections (four to six are typical) have been examined. Given that the effects of amphetamine are dosedependent and change over the course of repeated injections, the initial purpose in the present studies was to examine the course of place conditioning over a larger range of doses and number of injections than have typically been studied.

During the course of the experiment on the effect of dose and number of injections on place conditioning with amphetamine, we failed to observe any conditioned place preference; in fact, we observed that amphetamine produced a conditioned place avoidance. In the studies on dose and number of injections, we used a procedure of placing the animal in the end compartment $15 \mathrm{~min}$ prior to drug injection and then confining the animal for a further $30 \mathrm{~min}$ in the end box following drug injection. Although this procedure is not the one normally used in place conditioning studies, it has been used widely and successfully in other research on classical conditioning with drugs (e.g., see Siegel, 1983). The fact that, using this procedure, we found a conditioned place avoidance indicated the need for a parametric study of the effects of the CS-UCS interval in place conditioning. The final study involved the effect of varying the temporal relationship between drug injection and end box confinement on place conditioning with amphetamine.

\section{EXPERIMENT 1}

\section{Method}

\section{Subjects}

The subjects were 64 experimentally naive, male Sprague-Dawley rats (obtained from Canadian Breeding Farms, St. Constance, Quebec) that weighed $250-300 \mathrm{~g}$ at the beginning of the experiment. The animals were housed individually in wire mesh hanging cages, maintained on a 12:12-h light:dark cycle (lights on between 0700 and $1900 \mathrm{~h}$ ), and allowed access to food and water ad lib. One animal was excluded prior to the first choice test due to illness. In addition, 3 animals died prior to the final test day.

\section{Apparatus}

Eight identical, straight wooden alley boxes $(72 \times 28 \times 25 \mathrm{~cm})$ with Plexiglas lids were employed in the experiment. Each box had two distinctive end compartments $(28 \times 28 \times 25 \mathrm{~cm})$, which were separated from a middle area $(16 \times 28 \times 25 \mathrm{~cm})$ by guillotine doors. One end compartment was painted white and lined with woodchips; the opposite end compartment was painted black and had a bare floor. The middle area consisted of unpainted plywood. These place conditioning boxes were located in an experimental room that was separate from the animals' home cage room.

\section{Drugs}

d-Amphetamine sulfate was dissolved in physiological saline ( $0.9 \%$ sodium chloride). The animals were administered $0.05,0.1$, $0.5,2.0,5.0,7.5$, or $10.0 \mathrm{mg} / \mathrm{kg}$ of amphetamine intraperitoneally (i.p.).

\section{Procedure}

Initial screening. The initial screening phase occurred on 3 days, on which animals were transported in their individual cages, on a trolley, from their housing room to the experimental room. Subsequently, each animal was placed in and allowed access to a place conditioning box for $20 \mathrm{~min}$, and the time each subject spent in the two end compartments was manually recorded. Each rat's preferred and nonpreferred compartments were determined by the mean time spent in each of the two end compartments during the last 2 screening days.

Place conditioning and choice tests. Following the screening phase, groups of 8 animals were matched according to their preferred side (black or white) and the magnitude of their preference for it (amount of time spent in preferred side / amount of time spent in preferred side + amount of time spent in nonpreferred side), for assignment to different dose groups. The eight groups differed only with respect to the dose of amphetamine that they received (doses were $0.0,0.05,0.1,0.5,2.0,5.0,7.5$, or $10.0 \mathrm{mg} / \mathrm{kg}$ ). Animals from each of the matched groups were randomly assigned to the different dose groups.

Place conditioning consisted of 104 -day cycles. At the beginning of each training session, the animals were transported from the housing room to the experimental room. On the 1st and 3rd days of each 4-day cycle, each animal was placed in its nonpreferred side of the box and, 15 min later, was injected with its designated dose of amphetamine and returned to its nonpreferred side. After a further $30 \mathrm{~min}$, each animal was removed from the place conditioning chamber and returned to its home cage. On the 2nd and 4th days of each cycle, each animal was placed in its preferred side of the box and, $15 \mathrm{~min}$ later, injected with saline and returned to its preferred side. As on Days 1 and 3, the animais were confined in the place conditioning chamber for an additional $30 \mathrm{~min}$ following the injection, then removed and returned to their home cages.

Following each 4-day cycle, a choice test was administered. For each choice test, the animals were transported to the experimental room, and subsequently, each animal was placed in the middle compartment of a place conditioning chamber in which the guillotine doors were lowered, separating the middle compartment from the end compartments. Following a 30-sec delay, the guillotine doors were removed and the animal was allowed access to the entire chamber for $20 \mathrm{~min}$. The amount of time each animal spent in the two end compartments was manually recorded by an observer who was uninformed of the treatment that each rat had received. No injections of amphetamine or saline were given on any of the 10 choice tests.

\section{Statistical Analyses \\ A repeated measures ANOVA with randomized blocks was per- formed on the absolute time all animals spent in the drug-associated}


side (nonpreferred side for the $0-\mathrm{mg} / \mathrm{kg}$ group) during each of the 10 choice tests. As indicated previously, 1 animal died prior to the first choice test. In order to retain the data from the 7 other animals in this block, missing data for this animal were estimated for all 10 choice tests, using the procedure suggested by Kirk (1982). Degrees of freedom were adjusted to reflect the number of estimated data points. Additionally, as previously indicated, 3 animals died (1 from each of the groups with $5.0,7.5$, and $10.0 \mathrm{mg} / \mathrm{kg}$ ) between the 9th and 10th choice tests. The data for these animals were estimated for the 10th choice test, and the degrees of freedom were adjusted accordingly (Kirk, 1982). The overall analysis yielded a significant groups $\times$ trials interaction, and ANOVAs with randomized blocks were performed on each of the 10 test days. Pairwise comparisons (using the Duncan multiple ranges test, $p<.05$, two-tailed) were conducted on those test days for which the ANOVAs yielded a significant groups effect. When a druginjected group differed from the saline control group, a dependent $t$ test was used to determine whether or not the drug-injected group had spent significantly $(p<.05)$ less time on the drug-associated side during that test compared to screening.

\section{Results}

The mean ( $\pm S E M)$ amounts of time (in seconds) that animals spent on the nonpreferred side of the place conditioning chamber during the initial screening phase were $284.0( \pm 42.9), 277.4( \pm 48.7), 264.9( \pm 40.7), 265.4$ ( \pm 43.5$), 271.3( \pm 49.8), 262.5( \pm 36.8), 267.8( \pm 45.2)$, and $267.3( \pm 38.0)$ for dose groups with $0.0,0.05,0.1$, $0.5,2.0,5.0,7.5$, and $10.0 \mathrm{mg} / \mathrm{kg}$, respectively. As expected, analysis of the screening data revealed no significant group differences.

Figure 1 illustrates the mean time subjects in each of the eight groups spent on the drug-associated side (origi-

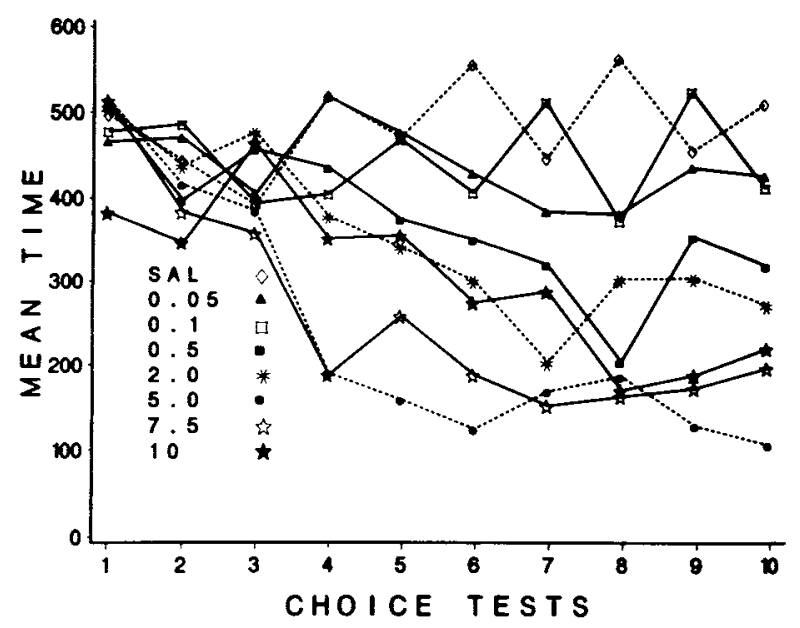

Figure 1. Mean amount of time (in seconds) rats in the different groups spent on the drug-associated side (originally nonpreferred side for the saline group) of the place conditioning chamber during each of the 10 choice tests. Pairwise comparisons were performed on Test Days 4, 5, 6, 7, 8, 9, and 10. Significant pairwise group differences $(p<.05)$ are summarized here according to drug dose and comparison group (with test days in parentheses): $10.0 \mathrm{mg} / \mathrm{kg}-$ Saline $(6,8,9,10), 0.05(9,10), 0.1(7,9,10) .7 .5 \mathrm{mg} / \mathrm{kg}-$ Saline $(4,6,7,8,9,10), 0.05(4,6,9,10), 0.1(7,9,10), 0.5(4)$. $5.0 \mathrm{mg} / \mathrm{kg}$-Saline $(4,5,6,7,8,9,10), 2(10), 0.05(4,5,6,9,10)$, $0.1(4,5,6,7,9,10), 0.5(4,5,6,10) .2 .0 \mathrm{mg} / \mathrm{kg}$-Saline $(6,7,8$, 10), $0.1(7,10), 0.05(10) .0 .5 \mathrm{mg} / \mathrm{kg}$-Saline $(6,8,10)$. nally nonpreferred side for the $0-\mathrm{mg} / \mathrm{kg}$ group) during each of the 10 choice tests. There were significant effects of training dose $[F(7,36)=2.62, p<.05]$ and trials $[F(9,50)=4.78, p<.01]$, and there was a significant training dose $\times$ trials interaction $[F(63,428)=1.62$, $p<.01]$.

Individual ANOVAs with randomized blocks yielded significant group effects on Test Days 4, 5, 6, 7, 8, 9, and 10 [all $F$ ratios were $\geq 2.70$, all $p s<.025$ ]. Pairwise comparisons performed on these test days indicated several differences between the saline group and various groups that received amphetamine. The group trained with $5 \mathrm{mg} / \mathrm{kg}$ differed from the saline group on all these test days. The group trained with $7.5 \mathrm{mg} / \mathrm{kg}$ differed from the saline group on all but Test Day 5 . The $10-\mathrm{mg} / \mathrm{kg}$ group differed from the saline group on Test Days 6, 8, 9, and 10 , while the $2-\mathrm{mg} / \mathrm{kg}$ group differed on Test Days 6,7 , 8 , and 10 . The $0.5-\mathrm{mg} / \mathrm{kg}$ group differed from the saline group on Test Days 6, 8, and 10. In addition to differences between the saline and amphetamine groups, there were also several differences obtained between groups that received various doses of amphetamine. All significant pairwise differences are summarized in the caption to Figure 1.

Whenever a drug-injected group differed from the saline control group on one of the test days, a dependent $t$ test was used to determine if the drug-injected group also spent significantly less time on the nonpreferred side than it did during screening. The $5-\mathrm{mg} / \mathrm{kg}$ group spent significantly less time on the drug-associated side than it did during screening on Test Days 5, 6, 7, 9, and 10; the $7.5-\mathrm{mg} / \mathrm{kg}$ group on Test Days 7,8, and 9; and the $10-\mathrm{mg} / \mathrm{kg}$ group on Test Day 8.

\section{Discussion}

No dose of amphetamine resulted in the animals' spending a significantly greater amount of time in the drugassociated side during any choice test, in comparison with the saline-injected control group. Thus there is no evidence that amphetamine produced a conditioned place preference. Amphetamine has been reported to produce a conditioned place preference with some of the doses used in the present experiment (e.g., Spyraki et al., 1982). In the present experiment, we used a procedure of placing the animal in the end compartment $15 \mathrm{~min}$ prior to drug injection and then confining the animal in that end compartment for a further $\mathbf{3 0}$ min following injection. It is possible that this particular temporal arrangement accounts for the lack of a conditioned place preference in the present experiment. This was investigated directly in Experiment 3 of the present report.

Although no evidence of conditioned place preferences was found in the present experiment, there was evidence of conditioned place avoidances due to amphetamine. First, groups injected with $\geq 0.5 \mathrm{mg} / \mathrm{kg}$ during training spent significantly less time on the drug-associated side than did the saline-injected control group during some of the choice tests. Second, on some of the choice tests, when a drug-injected group was different from the saline- 
injected control group, the drug-injected group also spent significantly less time on the drug-associated side than it had during screening. Thus, evidence of conditioned place avoidance is given by both between- and within-group comparisons.

During early choice tests, all groups-including the saline-injected control group-spent more time on the nonpreferred side than they did during screening. The finding that a saline-injected group will increase the amount of time spent on the saline-associated side has been reported by others (Schenk et al., 1986). The increase in time spent on the nonpreferred side by saline-injected animals is most likely due to some nonassociative process, such as habituation (e.g., Scoles \& Siegel, 1986). With the procedure used in the present experiment, amphetamine in doses of $\geq 0.5 \mathrm{mg} / \mathrm{kg}$ eventually counteracted this process. Furthermore, the fact that amphetamine-injected groups not only differed from the salineinjected control group, but also spent less time on the nonpreferred side than they had during screening indicates that amphetamine reversed this process, most likely due to some aversive properties. The aversive properties of amphetamine have been demonstrated in other paradigms, most notably taste aversion learning. The aversive properties of amphetamine were not apparent in the present experiment until at least the fourth or fifth choice test (8-10 amphetamine injections). In most place conditioning research, the effect of only a few injections prior to choice testing has been investigated, so it is possible that the aversive properties of amphetamine have not been noted in other studies because the number of injections was too small. Alternatively, the conditioned place avoidances seen in the present experiment might have been due to either the repeated choice testing or the particular temporal arrangement used. These two possibilities were investigated in Experiments 2 and 3, respectively.

\section{EXPERIMENT 2}

The second experiment was designed to determine whether or not repeated choice tests might have contributed to the conditioned place avoidances seen in Experiment 1 . There is some evidence that repeated drugfree testing can alter place preference conditioning. For example, Mithani et al. (1986) observed that the magnitude of an established, stimulant-induced conditioned place preference decreased over the course of consecutive choice tests. In Experiment 1, choice tests were administered following every two drug-conditioning trials. Because choice tests were conducted under "drug-free" conditions, the animals might have learned that the drug would not be administered on choice tests. If it is assumed that the failure to experience the drug effect, when the animal is in the usual drug-associated side, is aversive (e.g., see Hinson \& Siegel, 1980; Siegel, 1983; Wikler, 1973), then repeated drug-free choice tests might have resulted in conditioned avoidance of the usual amphet- amine side on test days. In order to assess this, four groups of animals receiving different doses of amphetamine $(0.0$, $0.5,2.0$, and $5.0 \mathrm{mg} / \mathrm{kg}$ ) were given place conditioning training identical to that in Experiment 1. However, repeated choice tests were omitted, and place conditioning was assessed following the completion of the training phase.

\section{Method}

Subjects. The subjects were 32 experimentally naive, male Sprague-Dawley rats (obtained from Canadian Breeding Farms, St. Constance, Quebec) that weighed $250-300 \mathrm{~g}$ at the onset of the experiment. These animals were maintained as in Experiment 1.

Apparatus. The apparatus was the same as that described in Experiment 1.

Drugs. d-amphetamine sulfate was dissolved in physiological saline $(0.9 \%$ sodium chloride). The animals were administered either $0.5,2.0$, or $5.0 \mathrm{mg} / \mathrm{kg}$ of amphetamine i.p.

Procedure. The animals in the different dose groups $(0.0,0.5$, 2.0 , and $5.0 \mathrm{mg} / \mathrm{kg}$ ) were exposed to screening and place conditioning sessions identical to those for the animals in Experiment 1. In contrast, however, multiple choice tests were not administered in Experiment 2. Rather, on those days, when a choice test would have been given at the end of a 4-day cycle, all animals simply remained undisturbed in their home cages. A single choice test (identical to that described in Experiment 1) was administered following the 10th 4-day place conditioning cycle. Thus, the number of drug administrations (20), the interval between drug administrations, and the latency from the onset of the experiment to the choice test of Experiment 2 were identical to those of the final (10th) choice test in Experiment 1.

Statistical analyses. An ANOVA with randomized blocks was performed on the absolute time all animals spent in the drugassociated side of the place conditioning chamber during the choice test. Subsequent pairwise comparisons were conducted using the Duncan multiple ranges test. All reported group differences were significant at $p<.05$. Dependent $t$ tests were used to determine whether the drug-injected groups spent significantly $(p<.05)$ less time on the drug-associated side during testing as opposed to screening.

\section{Results}

The mean $( \pm S E M)$ amounts of time animals spent in the nonpreferred side of the chamber during the initial screening phase were $237.4( \pm 47.6), 239.0( \pm 32.1)$, $227.1( \pm 27.7)$, and $235.0( \pm 32.1)$ for the $0.0-, 0.5-$, $2.0-$, and $5.0-\mathrm{mg} / \mathrm{kg}$ groups, respectively. As expected, there was no evidence of significant group differences.

Figure 2 shows the mean time that animals in the various dose groups spent in the nonpreferred side of the place conditioning chamber during the choice test. Statistical analysis revealed significant group differences $[F(3,21)$ $=5.556, p<.01]$. Subsequent pairwise comparisons indicated that all three groups that received amphetamine during place conditioning training $(0.5,2.0$, and $5.0 \mathrm{mg} / \mathrm{kg}$ ) spent significantly less time in the drugassociated side, in comparison with the saline control group, on the test day. There were no significant differences between the various groups that received amphetamine. Although the amphetamine-injected groups spent less time on the drug-associated side than did the saline- 


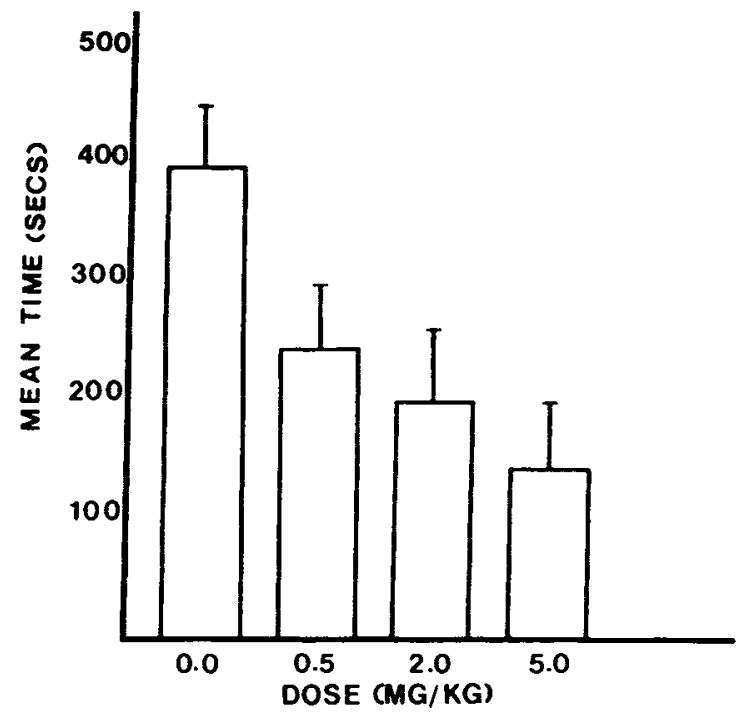

Figure 2. Mean ( $\pm S E M$ ) time animals in the various dose groups spent in the drug-associated side (originally nonpreferred side for the saline group) of the chamber during the choice test.

injected group, no drug-injected group spent less time on the nonpreferred side during testing as opposed to screening.

\section{Discussion}

Consistent with the results from Experiment 1, doses of amphetamine $\geq 0.5 \mathrm{mg} / \mathrm{kg}$ induced a conditioned place avoidance, in comparison with saline injection. Once again there was an increase in the amount of time salineinjected animals spent on their originally nonpreferred side, a finding that is typical in place conditioning research (e.g., see Scoles \& Siegel, 1986; Spyraki et al., 1982). Amphetamine counteracted the trend seen in saline-injected animals. However, in Experiment 2, amphetamine did not result in an actual decline in the amount of time spent on the nonpreferred side during test as opposed to screening. This result may be due to the more limited range of doses used in this experiment. In Experiment 1, only doses $\geq 5.0 \mathrm{mg} / \mathrm{kg}$ produced an actual decline in time spent on the nonpreferred side from screening to testing. Alternatively, the occurrence of a within-group decline in time spent on the nonpreferred side may depend on repeated drug-free choice testing. However, the finding of a difference between drug-injected and saline-injected groups clearly does not require repeated drug-free choice testing.

\section{EXPERIMENT 3}

In Experiments 1 and 2, animals were placed in a distinctive end box for $15 \mathrm{~min}$ prior to injection and then remained in that environment for $30 \mathrm{~min}$ following injection. This temporal arrangement may have been criti- cal in producing the place avoidances seen in these experiments. Consequently, a parametric investigation of various CS-UCS intervals with amphetamine in place conditioning seemed warranted. Research suggests that brain concentration of amphetamine following both subcutaneous (s.c.) and i.p. administrations rises quickly to a peak at $30 \mathrm{~min}$, followed by a much slower decline to baseline at $4 \mathrm{~h}$ postinjection (Kuhn \& Schonberg, 1978).

Five temporal arrangements of drug injection and end compartment confinement were examined. One interval was chosen to allow overlap of the CS with rising brain concentration (injection immediately before placement in the chamber for $30 \mathrm{~min}$ ), another to allow CS overlap with a falling brain concentration (injection $1.5 \mathrm{~h}$ before placement in the chamber), and a third interval in which brain concentration would be expected to have returned to baseline during the time of CS placement (injection $4 \mathrm{~h}$ before placement in the chamber). Additionally, an interval involving the injection of amphetamine immediately following offset of the CS was included, because this arrangement has been used in more traditional Pavlovian conditioning paradigms. Finally, a trace conditioning paradigm was selected, which involved the injection of amphetamine $4 \mathrm{~h}$ following the offset of the CS.

\section{Method}

Subjects. The subjects were 80 experimentally naive, male Sprague-Dawley rats (obtained from Canadian Breeding Farms, St. Constance, Quebec), weighing $250-300 \mathrm{~g}$ at the beginning of the experiment. These animals were maintained as in Experiments 1 and 2.

Apparatus. The apparatus was the same as that described in Experiments 1 and 2

Drugs. d-Amphetamine sulfate was dissolved in physiological saline $(0.9 \%$ sodium chloride). The animals were administered $2.0 \mathrm{mg} / \mathrm{kg}$ of amphetamine i.p.

Design and Procedure. The animals were not screened prior to the onset of training and were randomly assigned to one of the five different CS-UCS interval groups. Sixteen animals were assigned to each interval group. Half the animals in each CS-UCS interval group were randomly assigned to receive alternating amphetamine and saline injections, and the other half were assigned to a salineonly condition. Thus, there were 8 animals in each group. Finally, the end compartment for drug injections was randomly determined such that in the drug-injected group the black side was the designated drug-injection side for half the animals. Similarly, the black side served as the dependent-measure side for half the animals in the saline-only group. For each daily place conditioning training session, each animal spent a total of $30 \mathrm{~min}$ in the designated end compartment from the time of initial placement.

The procedural details of Experiment 3 were identical to those of Experiments 1 and 2, with the following exceptions: A choice test of 30 -min duration was given after every 12 injections $(6$ amphetamine alternated with 6 saline for groups receiving amphetamine). A total of 36 injections were given (18 amphetamine in the drug group), so data from three choice tests are reported. The results of Experiment 1 indicated that little place conditioning occurred until at least 6 drug injections had been given-hence the choice of 6 drug injections that preceded each choice test.

Statistical analyses. The data for each CS-UCS interval group were analyzed separately, using $2 \times 3$ mixed design ANOVAs. 
Between-group comparisons within each level of interval were based on the pooled error term calculated from all conditions (see Marascuilo \& Serlin, 1988, pp. 524-527).

\section{Results}

The mean time spent in the drug-designated side for the drug-injected groups (or the corresponding side for the saline-only groups) during each of the three choice tests by each of the two groups for each of the five CS-UCS arrangements is shown in Table 1. Only one significant effect was obtained: Animals that received amphetamine immediately after removal from the drug-associated side spent significantly less time on the drug-associated side in comparison with animals that received saline immediately following removal from the place conditioning box $[F(1,70)=4.00, p<.05]$.

In addition, an a priori comparison of the first choice test behavior of the drug and saline groups receiving injections immediately before placement in the place conditioning box (the typical arrangement for place conditioning with i.p. injections) revealed no significant difference.

\section{Discussion}

The only significant finding was that of a place avoidance, in animals that received an injection of amphetamine immediately following removal from the chamber. The CS-UCS arrangement in this group was somewhat similar to that employed in Experiments 1 and 2 in that the animals were exposed to their drug-designated side prior to being injected with amphetamine. In contrast to Experiments 1 and 2, however, in Experiment 3, the animals were not returned to the compartment following injection. In most place conditioning studies involving s.c. or i.p. injections, the drug injection is given immediately prior to placement in the place conditioning box. The present experiment included such an arrangement. The animals receiving amphetamine in this arrangement did spend more time on the drug-associated side than did

Table 1

Mean Time Spent on Amphetamine-Associated Side for Amphetamine- and Saline-Injected Groups during the Three Choice Tests in Experiment 3

\begin{tabular}{lllcr}
\hline \multirow{2}{*}{$\begin{array}{c}\text { CS-UCS } \\
\text { Interval Group }\end{array}$} & \multicolumn{1}{c}{ Injection } & 1 & 2 & 3 \\
\cline { 3 - 5 } 30 min after & saline & 731.0 & 767.6 & 757.5 \\
& amphetamine & 528.1 & 365.3 & 331.6 \\
Immediately before & saline & 735.1 & 805.4 & 812.8 \\
& amphetamine & 946.8 & 733.0 & 865.9 \\
1.5 h before & saline & 733.4 & 687.0 & 765.1 \\
& amphetamine & 738.1 & 875.9 & 778.6 \\
4 h before & saline & 550.1 & 750.5 & 538.1 \\
& amphetamine & 750.9 & 780.5 & 836.0 \\
$4 \mathrm{~h}$ after & saline & 832.9 & 700.9 & 608.8 \\
& amphetamine & 645.1 & 775.0 & 776.3 \\
\hline
\end{tabular}

Note-Groups are designated, in the leftmost column, according to when injections were given in relation to placement in the place conditioning box. The animals were confined in the box for $30 \mathrm{~min}$. the animals receiving only saline during the first choice test, but this difference was not significant. Perhaps evidence of a preference would have been obtained with this arrangement had choice tests been given after fewer amphetamine injections.

\section{GENERAL DISCUSSION}

The results of these experiments are consistent in demonstrating that animals injected with $\geq 0.5 \mathrm{mg} / \mathrm{kg}$ of amphetamine spend less time in the presence of stimuli associated with drug injections than do animals administered only saline with the same stimuli. There is also evidence that animals injected with $\geq 5.0 \mathrm{mg} / \mathrm{kg}$ in the presence of certain stimuli spend less time in the presence of those stimuli following drug injections (i.e., during choice tests) than they do prior to the start of injections (i.e., drug screening). Although conditioned place preferences have most commonly been reported with amphetamine (Carr \& White, 1983; Di Scala et al., 1985; Gilbert \& Cooper, 1983; Leone \& Di Chiara, 1987; Mackey \& Van der Kooy, 1985; Mithani et al., 1986; Sherman et al., 1980; Spyraki et al., 1982), conditioned avoidances have also been previously reported (Martin \& Ellinwood, 1974). Importantly, the conditioned place avoidances seen in the present experiments were manifested only after a number of injections greater than that most commonly used in place conditioning studies. Conditioned place preferences have been reported to occur with a small number of injections (usually four or less). With this number of injections, we did not observe any conditioned place preference, but there was no conditioned place avoidance either. Others (Martin \& Ellinwood, 1974; Schenk et al., 1986) have also failed to observe place conditioning with a small number of injections. In unpublished research in our laboratory, Wall, Hinson, and Lovenjack have found a conditioned place preference with morphine, so it is unlikely that the absence of a conditioned place preference with amphetamine in the present experiments is due to any physical aspect of our place conditioning apparatus or any obvious aspect of our procedure. Since amphetamine is suggested to have both positive and aversive qualities, it is possible that the aversive qualities are manifested in place conditioning after a larger number of injections than has heretofore been used in such studies. Conversely, the positive aspects of amphetamine may be more associable with contextual stimuli if only few injections are given, accounting for the conditional place preferences seen by others. There are several possible explanations of why positive and aversive properties of amphetamine may be manifest after differing numbers of injections. As mentioned previously, many effects of amphetamine change over the course of repeated administrations. With chronic amphetamine administration, there is an increase in druginduced stereotypy and dyskinetic behavior, both of which may be aversive. Perhaps concurrently with this increase in potential negative drug effects, there may be a diminution in the positive effects of the drug. The neurochem- 
ical consequences of amphetamine change over the course of extended administration (Fuxe \& Ungerstedt, 1970; Steranka \& Sanders-Bush, 1980). Although we did not measure neurochemical levels in the present study, it is possible that with the number of injections given, an altered neurochemical impact of amphetamine may explain the appearance of a conditioned avoidance with prolonged amphetamine administration.

In Experiments 1 and 2, the amount of time spent in the nonpreferred side increased from screening to the first few choice tests in all groups. The most parsimonious explanation of this increase is that it is the result of a nonassociative process and is clearly not dependent on any drug effect, since it occurred to an equal extent in the salineonly group and the drug-injected groups. After about 8-10 injections, depending on dose, the increase in time spent on the nonpreferred side was reduced in groups injected with $\geq 0.5 \mathrm{mg} / \mathrm{kg}$. Furthermore, groups injected with $\geq 5.0 \mathrm{mg} / \mathrm{kg}$ actually came to spend less time in the nonpreferred side than they had spent during screening. Chronic exposure to amphetamine in doses of $0.5 \mathrm{mg} / \mathrm{kg}$ or greater may counteract any nonassociative processes involved in the increase in time spent in the presence of originally nonpreferred stimuli from screening to choice tests. Alternatively, or in addition, an association may be formed between the stimuli of the nonpreferred side and aversive properties of amphetamine, and this aversive conditioning counteracts and eventually reverses the pattern seen in the saline-only group.

In the present experiments, a conditioned avoidance was found when the animal was placed in the end compartment before drug injection and drug injections were given either immediately after the animal was removed from the apparatus (Experiment 3) or 15 min after placement in the apparatus, upon which the animals were returned to the apparatus (Experiments 1 and 2). Eikelboom and Stewart (1981) have reported differences between conditioning to cues that precede amphetamine administration and conditioning to cues that follow it. It is clear that drug conditioning in general, and place conditioning in particular, may be influenced by the temporal relationship between drug injection and cue presentation.

\section{REFERENCES}

Balster, R. L., \& Schuster, C. R. (1973). A comparison of damphetamine, l-amphetamine, and methamphetamine selfadministration in rhesus monkeys. Pharmacology, Biochemistry \& Behavior, 1, 67-71.

BERGER, B. (1972). Conditioning of food aversions by injections of psychoactive drugs. Journal of Comparative \& Physiological Psychology, 81, 21-26.

Cappell, H., LeBlanc, A. E. (1971). Conditioned aversion to saccharin by a single administration of mescaline or amphetamine. Psychopharmacologica, 22, 352-356.

CaPpell, H., \& LeBlanc, A. E. (1973). Punishment of saccharin drinking by amphetamine in rats and its reversal by chlordiazepoxide. Journal of Comparative \& Physiological Psychology, 85, 97-104.

CAREY, R. J. (1973). Long-term aversion to saccharin solution induced by repeated amphetamine injections. Pharmacology, Biochemistry \& Behavior, 1, 265-270.
Carey, R. J., \& Goodall, E. B. (1973). Amphetamine-induced taste aversion: A comparison of d-versus l-amphetamine. Pharmacology, Biochemistry \& Behavior, 2, 325-330.

CARR, G. D., WhIte, N. M. (1983). Conditioned place preference from intra-accumbens but not intra-caudate amphetamine injections. Life Sciences, 33, 2551-2557.

Di Scala, G., Martin-Iverson, M. T., Phillips, A. G., \& Fibiger, H. C. (1985). The effects of progabide (SL 76002) on locomotor activity and conditioned place preference induced by $\mathrm{d}$-amphetamine. European Joumal of Pharmacology, 107, 271-274.

Eikelboom, R., \& Stewart, J. (1981). Conditioned temperature effects using amphetamine as the unconditioned stimulus. Psychopharmacology, 75, 96-97

Ellinwood, E. H., Balster, R. L. (1974). Rating the behavioral effects of amphetamine. European Journal of Pharmacology, 28, $35-41$.

FoG, R. (1970). Behavioral effects in rats of morphine and amphetamine and a combination of the two drugs. Psychopharmacologia, 16, 305-312.

FUXE, K., \& UNGERSTEDT, U. (1970). Histochemical, biochemical, and functional studies on central monoamine neurons after acute and chronic amphetamine administration. In E. Costa \& S. Garattini (Eds.), amphetamines and related compounds (pp. 257-288). New York: Raven Press.

Gilbert, D., \& CoOper, S. J. (1983). P-phenylethylamine, d-amphetamine and l-amphetamine-induced place preference conditioning in rats. European Journal of Pharmacology, 95, 311-314.

Hinson, R. E., \& SiEgel, S. (1980). The contribution of Pavlovian conditioning to ethanol tolerance and dependence. In H. Righter \& C. Crabbe (Eds.), Alcohol tolerance, dependence and addiction (pp. 181-199). Amsterdam: Elsevier/North-Holland Biomedical Press.

KIRK, R. E. (1982). Experimental design: Procedures for the behavioral sciences (2nd ed.). Monterey, CA: Brooks/Cole.

KuHN, C. M., \& SCHONBERG, S. M. (1978). Metabolism of amphetamine after acute and chronic administration to the rat. Journal of Pharmacology \& Experimental Therapeutics, 207, 544-554.

LE MAGNEN, J. (1969). Peripheral and systemic actions of food in caloric regulation of intake. Annals of the New York Academy of Sciences, 157, 1126-1157.

Leone, P., \& Di Chiara, G. (1987). Blockade of D-1 receptors by SCH 23390 antagonizes morphine- and amphetamine-induced place preferences. European Journal of Pharmacology, 135, 251-254.

MACKEY, W. B., \& VAN DER KOOY, D. (1985). Neuroleptics block the positive reinforcing effects of amphetamine but not of morphine as measured by place conditioning. Pharmacology, Biochemistry \& Behavior, 22, 101-105.

Marascuilo, L. A., \& Serlin, R. C. (1988). Statistical methods for the social and behavioral sciences. New York: W. H. Freeman.

Martin, J. C., Ellinwood, E. H. (1974). Conditioned aversion in spatial paradigms following methamphetamine injection. Psychopharmacologia, 36, 323-335.

Mithani, S., Martin-Iverson, M. T., Phillips, A. G., \& Fibiger, H. C. (1986). The effects of haloperidol on amphetamine and methylphenidate-induced conditioned place preferences and locomotor activity. Psychopharmacology, 90, 247-252.

PiCKeNs, R. (1968). Self-administration of stimulants by rats. International Journal of Addictions, 3, 215-221.

Schenk, S., Hunt, J., Malovechko, R., Robertson, A., KLukowski, G. , \& AMrT, Z. (1986). Differential effects of isolation housing on the conditioned place preference produced by cocaine and amphetamine. Pharmacology, Biochemistry \& Behavior, 24, 1793-1796.

SCOLES, M. T., SiEgeL, S. (1986). A potential role of saline trials in morphine-induced place-preference conditioning. Pharmacology, Biochemistry \& Behavior, 25, 1169-1173.

Segal, D., \& MANDELL, A. J. (1974). Long-term administration of d-amphetamine: Progressive augmentation of motor activity and stereotypy. Pharmacology, Biochemistry \& Behavior, 2, 249-255.

Segal, D. S., Weingerger, S. B., Cahill, J. C., MCCunney, S. (1980). Multiple daily amphetamine administrations: Behavioral and neurochemical alterations. Science, 207, 904-907. 
Sherman, J. E., Roberts, R., Roskam, S. E., \& Holman, E. W. (1980). Temporal properties of the rewarding and aversive effects of amphetamine in rats. Pharmacology, Biochemistry \& Behavior, 13, $597-599$.

Siegel, S. (1983). Classical conditioning, drug tolerance \& drug dependence. In Y. Israel, F. B. Glaser, H. Kalant, R. E. Popham, W. Schmidt, \& R. E. Smart (Eds.), Research advances in alcohol and drug problems (Vol. 7, pp. 207-246). New York: Plenum.

Spyraki, C., Fibiger, H. C., Phillips, A. G. (1982). Dopaminergic substrates of amphetamine-induced place preference conditioning. Brain Research, 253, 185-193.

Steranka, L. R., \& Sanders-Bush, E. (1980). Long-term effects of continuous exposure to amphetamine on brain concentration and syn- aptosomal uptake in mice. European Journal of Pharmacology, 65, 439-443.

Wall, A. M., Hinson, R. E., Lovenjack, T. (1989). The effect of the CS-UCS interval on place conditioning with morphine. Unpublished manuscript.

WIKLER, A. (1973). Conditioning of successive adaptive responses to the initial effects of drugs. Conditioned Reflex, 8, 193-210.

WISE, R. A., YoKeL, R. A., \& DEWITT, H. (1976). Both positive reinforcement and conditioned aversion from amphetamine and apomorphine in rats. Science, 191, 1273-1274.

(Manuscript received March 15, 1989; revision accepted for publication May 24, 1990.) 